\title{
ONOMÁVEIN
}

Journal of linguistics, philology and translation

\section{The use of discourse markers in oral discourse in EFL classroom by pre-service EFL teachers}

\section{Oleksandr Kapranov}

Western Norway University of Applied Sciences

Special

Issue

- VI -

Language

Teaching

Research from a Global

Perspective

2020
ONOMÁZEIN | Special Issue VI - Language Teaching Research from a Global Perspective: 126-146 DOI: 10.7764/onomazein.ne6.07

ISSN: 0718-5758

\section{(c) $($ i $)$}

Oleksandr Kapranov : Department of Language, Literature, Mathematics and Interpreting, Western Norway University of Applied Sciences | E-mail: oleksandr.kapranov@hvl.no 


\section{Abstract}

This article presents and discusses a computer-assisted case study of the use of discourse markers (further-'DMs') in oral discourse in English as a Foreign Language (EFL) by pre-service teachers in Norway. The aim of this case study is to explore the use of DMs by pre-service teachers (further referred to as 'participants') in EFL classroom by means of analysing the participants' answers to the questionnaire that is designed to address the use of DMs in oral discourse in EFL after their school practice. The case study is informed by the view of DMs as "sequentially dependent elements that bracket units of talk" (Schiffrin, 1987: 31). The quantitative analysis of the participants' questionnaires in statistical program SPSS version 18.0 (2009) indicates that the participants' repertoire of DMs in their oral discourse in EFL classroom consists of such DMs as also, and, as, because, besides, but, especially, if, OK, or, so, and then. Additionally, the participants note that they do not use the following DMs during their teaching practice at school, e.g. indeed, moreover, and rather. These findings and their linguo-didactic implications will be further discussed in the article.

Keywords: discourse marker (DM); English as a Foreign Language (EFL); oral classroom discourse; pre-service EFL teacher. 


\section{Introduction}

This article presents and discusses a computer-assisted case study that aims at elucidating how pre-service teachers of English as a Foreign Language (EFL) use English discourse markers (henceforth-'DMs') in their oral classroom discourse. In this case study, oral classroom discourse is viewed "as a context in its own right, or rather a series of interrelated contexts, jointly created and defined by the participants: the teacher and learners" (Walsh, 2002: 3-4). The case study follows the definition of DMs as sequentially dependent linguistic elements that bracket oral discursive units and "signal relations between units of talk by virtue of their syntactic, semantic properties" (Schiffrin, 1987: 40).

Previous research indicates that DMs "function in cognitive, expressive, social, and textual domains" (Maschler \& Schiffrin, 2015: 189). DMs appear to be associated with a variety of pragmatic purposes, genre conventions, and registers that are expected in a given socio-communicative situation or a domain of experience (Biber, 2006; Matras, 2000). For instance, the DM well occurs in informal oral discourse, whereas the DM therefore eventuates in the formal register of English (Crible \& Cuenca, 2017; Kapranov, 2018). Irrespective of the register, DMs constitute a feature of monolingual (Schiffrin, 1987), bilingual (Maschler, 2000), and EFL discourse (Kapranov, 2017). In particular, in EFL classroom discourse DMs are theorised "to serve structural, pragmatic and interactional purposes" (Castro \& Marcela, 2009: 77). It is logical to assume that oral discourse in a typical EFL classroom involves a certain repertoire of DMs that are employed by EFL teachers.

Currently, however, there is insufficient research on how English DMs are used in oral discourse in an EFL classroom by pre-service EFL teachers in Norway. Specifically, little is known about the pre-service EFL teachers' repertoire of English DMs and the discursive register this repertoire is associated with. The novelty of the study further presented and described in this article involves a computer-assisted analysis of the questionnaire that is designed to assess the use of English DMs by a group of pre-service EFL teachers after their teaching practice at a range of lower secondary schools in Norway. The study involves ten pre-service EFL teachers (further-'participants'), who are instructed to answer questions concerning the use of English DMs during their EFL teaching practice at school. The questionnaire is based upon a repertoire of English DMs that is employed by an experienced in-service EFL teacher in realistic EFL contexts. The specific aim of the study is to examine the participants' questionnaires in order to establish which English DMs they use in their oral discourse in EFL classroom settings.

Further, this article is structured as follows. First, the background notions associated with DMs and the literature review involving DMs in oral discourse in EFL classroom interactions will be outlined. Thereafter, the present study will be introduced and discussed. Finally, conclusions and linguo-didactic suggestions associated with the use of English DMs in EFL classroom interactions will be provided. 


\section{Theoretical framework}

Prior research in linguistics and EFL studies is suggestive of multiple definitions and perspectives on DMs. As posited by Schiffrin (2001: 60), the differences in approaches and definitions "stem from theoretical assumptions and goals, methodological practices, and choice of data...." In this regard, Campillos-Llanos and González-Gómez (2014) indicate that due to the discrepancies in methodological approaches towards the definition of DMs, a comprehensive and unified taxonomy of DMs is absent in the literature. Currently, there are several well-established and widely cited definitions of DMs (Fraser, 1999; Schiffrin, 2001). In particular, Fraser (1999) regards DMs as lexical expressions that are

drawn primarily from the syntactic classes of conjunctions, adverbs, and prepositional phrases. With certain exceptions, they signal a relationship between the interpretation of the segment they introduce, S2, and the prior segment, S1. They have a core meaning, which is procedural, not conceptual, and their more specific interpretation is 'negotiated' by the context, both linguistic and conceptual. (Fraser, 1999: 931)

Another definition of DMs is found in a seminal work by Schiffrin (1987), where DMs are seen as "sequentially dependent elements that bracket units of talk" (Schiffrin, 1987: 31). To specify this definition, Schiffrin (2001) considers DMs as "a set of linguistic expressions comprised of members of word classes as varied as conjunctions (e.g. and, but, or), interjections (oh), adverbs (now, then), and lexicalized phrases (y' know, I mean)" (Schiffrin, 2001: 57). In Schiffrin's $(1987,2001)$ approach, DMs are theorised to display relationships between adjacent utterances, as well as between wider discursive structures. Expanding upon the premises of Schiffrin's (1987, 2001) view of DMs, Romero-Trillo (2007) proposes the discourse-cognitive model of DMs. In this model, DMs are theorised to be "dynamic elements that serve to mould the cognitive stance of the speaker-hearer relationship according to the pragmatic force of an utterance in a given context" (Romero-Trillo, 2007: 82). It should be noted that the present research is informed by Schiffrin's $(1987,2001)$ definition of DMs, since it is argued to be optimally suited to analyse oral discourse.

Previous research in applied linguistics indicates that DMs play a substantial role in oral discourse (Carter \& McCarthy, 2006). For instance, such DMs as okay, well, now are thought to be "restricted primarily to spoken discourse" (Carter \& McCarthy, 2006: 66), whilst DMs henceforth, therefore, etc., are associated with written discourse (Kapranov, 2018). In contrast to written discourse, however, oral discourse is characterised by those DMs whose meaning and pragmatic functions are ambiguous and multifunctional (Carter \& McCarthy, 2006; Crible \& Cuenca, 2017). Presumably, the multifunctionality of DMs appears to be associated with pragma-semantic ambiguity of oral discourse. In particular, oral discourse is characterised by a limited number of DMs that "tend to be used with a relatively wide range of meanings and where context is a key-element in discourse production and processing" (Crible \& Cuenca, 2017: 155). Arguably, oral discourse is facilitative of those functions of DMs that are related 
to expressing the interlocutor's response to the preceding and following discourse chunks, back-channelling, hedging (Fox Tree, 2010), and "effecting cooperation, sharing, or intimacy between speaker and hearer, including confirming shared assumptions, checking or expressing understanding" (Liu, 2013: 150).

In terms of the acquisition of DMs, Fox Tree (2010: 273) posits that "the meaning of discourse markers has to be learned, both in first and second language acquisition." This observation is echoed by Sankoff and her colleagues (1997), who emphasise that "discourse markers are of particular interest because they constitute an aspect of the language not taught in school" (Sankoff et al., 1997: 193). This view is in concert with Hays (1992), who suggests that DMs are acquired in a developmental order by EFL learners. Commenting on Hays (1992), Koczogh (2007) argues that those "DMs which have bigger semantic weight and are taught first and overtly are on the ideational plane and these are the ones that are present first in the speech of language learners" (Koczogh, 2007: 46). Arguably, the acquisition of DMs by EFL learners is influenced by several variables, such as a learner's sojourn abroad (Hellermann \& Vergun, 2007), the level of bilingualism (Maschler, 2000), and a learner's exposure to the EFL teacher's input (Rose, 2005). Presumably, another variable involved in the acquisition of English DMs would be associated with oral discourse in EFL classroom that is comprised of communicative interaction between the teacher and the student, the teacher and the student group, and amongst the student group as well (Kapranov, 2019). Further, I will present a number of prior studies associated with the use of DMs in oral classroom discourse in a variety of EFL settings.

Previous research associated with the use of English DMs in oral discourse in EFL settings is well represented in applied linguistics and EFL studies. Recent research investigates the use of DMs by EFL learners and EFL instructors whose first language (LI) is Chinese (Ding \& Wang, 2015; Fung \& Carter, 2007; Liu, 2013; Shahbaz, Sheikh, \& Ali, 2013), Croatian (Vickov \& Jakupčević, 2017), Farsi (Kalajahi \& Abdullah, 2012; Tavakoli \& Karimnia, 2017), Indonesian (Suparno \& Setyaningsih, 2015), Spanish (Llinares-García \& Romero-Trillo, 2008), and Turkish (Aşık \& Cephe, 2013; Özer \& Okan, 2018). A meta-analysis of prior studies involving DMs in EFL classroom discourse is suggestive of several research foci that are associated with i) the contrastive use of DMs by EFL learners and English Lı speakers (Așık \& Cephe, 2013; Ding \& Wang, 2015; Fung \& Carter, 2007; Llinares-García \& Romero-Trillo, 2008), ii) the use of DMs in oral classroom discourse by nonnative EFL teachers (Suparno \& Setyaningsih, 2015; Vickov \& Jakupčević, 2017), iii) the use of DMs by EFL learners in the implicit mode of instruction (Hellermann \& Vergun, 2007), iv) the perceived use of DMs in EFL classroom (Kalajahi \& Abdullah, 2012), v) the role of gender in the use of DMs by EFL learners (Tavakoli \& Karimnia, 2017), and vi) the transfer of DMs from the learners' Lı into oral discourse in EFL (Liu, 2013).

As previously mentioned, the contrastive use of DMs by EFL learners and English Lı speakers is present in the work by Așık and Cephe (2013), Fung and Carter (2007), Llinares-García and Romero-Trillo (2008), and Özer and Okan (2018). In particular, Aşık and Cephe (2013) argue that 
Turkish LI EFL learners' repertoire of DMs in oral discourse in English is significantly different from that of the English L1 speakers. Similar findings are reported by Özer and Okan (2018), who suggest that Turkish LI EFL teachers underuse DMs compared to the English LI EFL teachers in the study. In similar fashion, Fung and Carter (2007) argue that English Li speakers use DMs for a wider variety of pragmatic functions compared to Cantonese LI EFL learners, who prefer a limited number of DMs (e.g., and, but, because, ok, and so).

The use of English DMs by Cantonese LI EFL teachers is further investigated by Ding and Wang (2015), who aim at contrasting how DMs are used by English L1 and Cantonese L1 EFL teachers in an EFL classroom. Ding and Wang (2015) indicate that the DMs ok, so, and, right, and now are frequently used by English L1 EFL teachers, as well as by their Cantonese L1 counterparts. Whilst English L1 EFL teachers overuse ok, their Cantonese L I colleagues "tend to rely heavily on certain DMs in their speech, using them frequently in order to gain time for information processing" (Ding \& Wang, 2015: 72). In concert with Ding and Wang (2015), Shahbaz and the colleagues (2013) argue that Chinese L1 EFL teachers excessively use such DMs as so, and, but, ok, well, and right in comparison to the use of DMs by a group of English L1 teachers (Shahbaz, Sheikh, \& Ali, 2013).

Analogous to the afore-mentioned studies that focus on the contrastive use of DMs, LlinaresGarcía and Romero-Trillo (2008) note that there is a divergent use of DMs by English L1 and nonnative teachers of English in Content and Language Integrated Learning (CLIL) contexts. In particular, Llinares-García and Romero-Trillo (2008) indicate that non-native CLIL teachers employ substantially more DMs than their English LI CLIL colleagues. Specifically, these findings refer to "the instructional register, possibly because of its argumentative nature and its cognitive implications for the learner" (Llinares-García \& Romero-Trillo, 2008: 202).

In contrast to the above-mentioned research focus, Vickov and Jakupčević (2017) investigate the occurrence and frequency of DMs in EFL classroom discourse that involves EFL teachers and students. In particular, they explore how the DMs ok, so, and are distributed in oral discourse in an EFL classroom. It has been found in that study that the nonnative EFL teachers use those DMs that are "typical of classroom management and classroom discourse organization, with no significant differences in the patterns of DM use with the primary and secondary school students" (Vickov \& Jakupčević, 2017: 649). Similarly, Suparno and Setyaningsih (2015) examine the occurrence and functions of DMs used by the EFL teachers. They suggest that DMs contribute to the EFL teachers' coherent discourse in their classroom interactions with the students.

The focus on the EFL learners' acquisition of English DMs in implicit instructional settings is reported by Hellermann and Vergun (2007). They investigate oral classroom discourse by EFL learners who have not been explicitly exposed to the use of English DMs. Hellermann and Vergun (2007) explore the use of the DMs you know, like, and well. They note that proficient EFL learners use those DMs that are not found in the EFL teacher's classroom discourse. Hence, 
Hellermann and Vergun (2007) suggest that certain English DMs have been acquired by the EFL learners implicitly without the teacher's explicit instructional input.

The focus on the perceptive use of DMs in the EFL classroom is described by Kalajahi and Abdullah (2012), who examine what Iranian EFL teachers think about the use of English DMs. The examination is carried out by means of a survey. The findings in the study reveal that the majority of EFL teachers in Iran "are simply not fully aware of the functionality of DMs in foreign language learning and teaching” (Kalajahi \& Abdullah, 2012: 2005).

The research focus on the role of gender in the use of English DM in EFL discourse is discussed by Tavakoli and Karimnia (2017). Based upon realistic EFL classroom data, it is posited that female EFL learners employ a significant number of DMs. Specifically, Tavakoli and Karimnia (2017) have found that female EFL learners frequently use the DMs and, but, because, by the way, and sure.

The focus on the EFL learner's transfer of DMs from their LI into EFL is elaborated upon by Liu (2013), who reports that certain Chinese DMs influence the use of the corresponding English DM in oral communication in English by Chinese L1 EFL learners (Liu, 2013: 149). Whereas Chinese LI EFL speakers exhibit a tendency to overuse DMs I think, yeah, and yes, they underuse such English DMs as like, just, y’know, I mean, sort of / kind of, etc. (Liu, 2013: 169).

As evident from the literature, the research foci on the use of English DMs in oral discourse in EFL classroom settings are reflected in a substantial number of publications. However, todate little is known about the use of DMs in EFL classroom in Norway, especially as far as the use of DMs by pre-service EFL teachers is concerned. In the following section, I will introduce a case study that addresses this issue.

\section{Methodology}

Whilst there is a substantial body of previous studies associated with the use of DMs in EFL settings, the state-of-the art research on the repertoire of English DMs used by pre-service EFL teachers whose LI is Norwegian is underrepresented. This study seeks to generate new knowledge about the use of DMs in oral discourse in a Norwegian EFL classroom by the participants who are pre-service EFL teachers studying at a large university in Norway. Specifically, the study aims at analysing written responses to the questionnaire that is associated with the use of English DMs by the participants during their teaching practice in Year 8 at a number of lower secondary schools in Norway.

\subsection{Hypothesis and specific research aims}

In concert with previous research (Castro \& Marcela, 2009; Vickov \& Jakupčević, 2017), the present hypothesis involves an assumption that the participants' use of the English DM in a typical EFL classroom in Year 8 would be guided by the linguo-pragmatic instructional contexts 
of EFL teaching and learning. Based upon this assumption, the following specific research aims of the study are formulated:

i) to establish whether or not the repertoire of English DMs that the participants use in oral classroom discourse during their teaching practice at school would be qualitatively different from and/or similar to that of the experienced EFL teacher;

ii) to investigate whether or not the participants' repertoire of English DMs in their oral classroom discourse would be marked by formal and/or informal registers of the English language.

These research aims will be investigated by means of the following methodological procedures: a) collecting a corpus of English DMs used in oral classroom discourse by an experienced EFL teacher in order to compile the questionnaire to be distributed to the participants, and b) soliciting the participants' answers to the questionnaire in order to analyse them quantitatively in the statistical package SPSS version 18.0 (2009).

\subsection{Participants}

10 participants ( 8 females and 2 males, mean age $=21$ y.0., standard deviation $=1,7$ ) took part in the study. The participants were enrolled in the EFL undergraduate teacher training course at a large university in Norway. The participants' LI was Norwegian and English was their foreign language (FL). The participants were informed about the experimental procedure by the author of the present article. The participants signed the consent form that allowed the author to use the participants' data for scientific purposes. All identifying information and the participants' real names were coded to ensure confidentiality. The codes used in the study were P1 (female), P2 (female), P3 (male), P4 (male), P5 (female), P6 (female), P7 (female), P8 (female), P9 (female), and P10 (female), i.e. in the coding scheme the letter 'P' stood for 'participant', followed by gender and the number from 1 to 10.

\subsection{Materials}

The materials involved a structured questionnaire that was distributed to the participants. The questionnaire was comprised of a set of questions associated with the use of English DMs in EFL classroom discourse, e.g. also, and, as, because, besides, but, especially, hopefully, however, if, indeed, moreover, oh, ok, or, perhaps, rather, so, then, and yet. Specifically, each of the previously mentioned DMs was followed by the questions: a) Do you think that students in Year 8 know the translation of this word? Please, answer YES or NO. Then, please comment on your answer in detail; b) Do you think that students in Year 8 use this word in oral communication in their EFL classroom? Please, answer YES or NO. Then, please comment on your answer in detail; c) Do you think that students in Year 8 use this word in written communication in their EFL classroom? Please, answer YES or NO. Then, please comment on your answer in detail; d) Do you think that students 
in Year 8 experience difficulties with using this word? Please, answer YES or NO. Then, please comment on your answer in detail; e) Did you use this word in your oral communication with the students in Year 8? Please, answer YES or NO. Then, please comment on your answer in detail.

The questionnaire was compiled by using the corpus of written transcripts of oral classroom discourse by an experienced in-service EFL teacher. The in-service EFL teacher was a 62 y.o. female with 40 years of teaching experience at a range of secondary schools in Norway. The in-service EFL teacher's LI was Norwegian, and English was her FL. The in-service teacher gave her consent to be observed at her typical EFL lessons in Year 8 for the duration of two weeks (i.e., 5 contact teaching hours in total). The observations involved written transcripts of the in-service teacher's oral discourse. The transcripts were written down by hand by the author of the article. No technical aids were used during the whole time of the observation period to ensure the ethical guidelines. No transcripts of oral discourse by the students in Year 8 were made to ensure that the students' confidentiality was protected. The hand-written transcripts of the in-service teacher's oral discourse were converted into files typed on a portable computer and analysed in the software program WordSmith (Scott, 2008) in order to calculate the frequency of DMs per 1000 words. The frequency of the DMs used by the in-service teacher was summarised by the author of the present article and provided in Table 1 below:

\section{TABLE 1}

Frequency of DMs used by the in-service teacher in her oral classroom discourse

\begin{tabular}{ll} 
DM & FREQUENCY PER 1000 WORDS \\
Also & $4(0,2 \%)$ \\
\hline And & $70(3,4 \%)$ \\
\hline As & $3(0,15 \%)$ \\
\hline Because & $9(0,4 \%)$ \\
\hline Besides & $1(0,05 \%)$ \\
\hline But & $25(0,7 \%)$ \\
\hline Especially & $1(0,05 \%)$ \\
\hline Hopefully & $1(0,05 \%)$ \\
\hline However & $1(0,05 \%)$ \\
\hline If & $6(0,3 \%)$ \\
\hline Indeed & $1(0,05 \%)$ \\
\hline Moreover & $1(0,05 \%)$ \\
\hline Oh & $2(0,1 \%)$ \\
\hline OK & $13(0,6 \%)$ \\
\hline Or & $15(0,7 \%)$ \\
\hline
\end{tabular}




\begin{tabular}{ll}
\hline Perhaps & $1(0,05 \%)$ \\
\hline Rather & $1(0,05 \%)$ \\
\hline So & $2(0,1 \%)$ \\
\hline Then & $1(0,05 \%)$ \\
\hline Yet & $1(0,05 \%)$ \\
\hline
\end{tabular}

The in-service teacher's use of the DMs illustrated in Table 1 could be further exemplified by the following excerpts: i) "And please, write in pairs"; ii) "Ok, I think we stop now"; iii) "But...but now we are going to work with chapter 8"; iv) "As you heard, we start celebrating Christmas in December. However, in other countries there are different holidays at that time"; v) "If you have further questions, I will tell you more about the task."

\subsection{Procedure and method}

The participants were provided with the print-outs of the questionnaire at a seminar in $\mathrm{EFL}$ didactics after they returned from their school practice. The participants were instructed to read the questionnaire carefully and recall their classroom situations prior to filling in the questionnaire. The participants were told to provide as much information as possible after each of the YES/NO questions on the blank lines that followed the questions.

The participants were given 90 minutes for the execution of the task. Once the questionnaires were filled in by the participants, they were collected by the author of the article and analysed. The quantitative analysis of the questionnaires was conducted by means of the statistical package SPSS 18.0 (2009). The results yielded by SPSS 18.0 (2009) were summarised in Table 2 in the following sub-section of the article.

\section{Results and discussion}

The analysis of the participants' questionnaires in the statistical package SPSS version 18.0 (2009) has yielded descriptive statistics that are summarised in Table 2 below.

\section{TABLE 2}

Participants' use of the English DMs in their oral classroom discourse

\begin{tabular}{llllll} 
& PARTICIPANTS' & STUDENTS' & STUDENTS' & STUDENTS' & STUDENTS' \\
DM & USE & WIFFICULTIES & USE OF DM & USE OF DM & AWARENESS OF \\
WITH DM & ORALLY & IN WRITING & DM TRANSLATION \\
\hline Also & $100 \%$ yes & $100 \%$ no & $100 \%$ yes & $100 \%$ yes & $100 \%$ yes \\
\hline And & $100 \%$ yes & $100 \%$ no & $100 \%$ yes & $100 \%$ yes & $100 \%$ yes \\
\hline
\end{tabular}




\begin{tabular}{|c|c|c|c|c|c|}
\hline As & $100 \%$ yes & $30 \%$ yes & $80 \%$ yes & $90 \%$ yes & $100 \%$ yes \\
\hline & & $70 \%$ no & $20 \%$ no & 10\% no & \\
\hline Because & $100 \%$ yes & $100 \%$ no & $100 \%$ yes & $100 \%$ yes & $100 \%$ yes \\
\hline \multirow[t]{2}{*}{ Besides } & $100 \%$ yes & $20 \%$ yes & $100 \%$ no & $60 \%$ yes & $40 \%$ yes \\
\hline & & $80 \%$ no & & $40 \%$ no & $60 \%$ no \\
\hline But & $100 \%$ yes & 100\% no & $100 \%$ yes & $100 \%$ yes & $100 \%$ yes \\
\hline Especially & $100 \%$ yes & $100 \%$ no & $100 \%$ yes & $100 \%$ yes & $100 \%$ yes \\
\hline \multirow[t]{2}{*}{ Hopefully } & $30 \%$ yes & $30 \%$ yes & $30 \%$ yes & $10 \%$ yes & $90 \%$ yes \\
\hline & $70 \%$ no & $70 \%$ no & $70 \%$ no & $90 \%$ no & $10 \%$ no \\
\hline \multirow[t]{2}{*}{ However } & $80 \%$ yes & $100 \%$ yes & $100 \%$ no & $100 \%$ no & $100 \%$ no \\
\hline & $20 \%$ no & & & & \\
\hline If & $100 \%$ yes & $100 \%$ no & $100 \%$ yes & $100 \%$ yes & $100 \%$ yes \\
\hline \multirow[t]{2}{*}{ Indeed } & $10 \%$ yes & $20 \%$ yes & $10 \%$ yes & $10 \%$ yes & $80 \%$ yes \\
\hline & $90 \%$ no & $80 \%$ no & $90 \%$ no & $90 \%$ no & $20 \%$ no \\
\hline \multirow[t]{2}{*}{ Moreover } & $10 \%$ yes & $100 \%$ yes & $100 \%$ no & $100 \%$ no & $100 \%$ no \\
\hline & $90 \%$ no & & & & \\
\hline \multirow[t]{2}{*}{ Oh } & $50 \%$ yes & $100 \%$ no & $90 \%$ yes & $80 \%$ yes & $100 \%$ yes \\
\hline & $50 \%$ no & & 10\% no & $20 \%$ no & \\
\hline OK & $100 \%$ yes & $100 \%$ no & $100 \%$ yes & $100 \%$ yes & $100 \%$ yes \\
\hline Or & $100 \%$ yes & $100 \%$ no & $100 \%$ yes & $100 \%$ yes & $100 \%$ yes \\
\hline \multirow[t]{2}{*}{ Perhaps } & $80 \%$ yes & $100 \%$ no & $20 \%$ yes & $40 \%$ yes & $90 \%$ yes \\
\hline & $20 \%$ no & & $80 \%$ no & $60 \%$ no & 10\% no \\
\hline \multirow[t]{2}{*}{ Rather } & $30 \%$ yes & $100 \%$ yes & $100 \%$ no & $100 \%$ no & $100 \%$ no \\
\hline & $70 \%$ no & & & & \\
\hline So & $100 \%$ yes & $100 \%$ no & $100 \%$ yes & $100 \%$ yes & $100 \%$ yes \\
\hline \multirow[t]{2}{*}{ Then } & $100 \%$ yes & $90 \%$ no & $90 \%$ yes & $90 \%$ yes & $100 \%$ yes \\
\hline & & $10 \%$ yes & $10 \%$ no & 10\% no & \\
\hline \multirow[t]{2}{*}{ Yet } & $90 \%$ yes & $90 \%$ no & $90 \%$ yes & $90 \%$ yes & $90 \%$ yes \\
\hline & 10\% no & $10 \%$ yes & $10 \%$ no & $10 \%$ no & 10\% no \\
\hline
\end{tabular}

As previously mentioned in section 3.1 of the present article, the specific research aims of the study are i) to investigate whether or not the participants' repertoire of English DMs in their oral classroom discourse would be qualitatively different from or similar to that of the experienced EFL teacher, and ii) to ascertain whether or not the participants' repertoire of 
English DMs in their oral classroom discourse would be marked by the informal and/or formal registers of the English language.

As far as the first research aim is concerned, it is seen in Tables 1 and 2 that the participants' repertoire of English DMs appears to be qualitatively similar to that of the experienced EFL teacher. In particular, $100 \%$ of the participants indicate that they use 12 out of 20 DMs that are employed by the experienced in-service EFL teacher, such as also, and, as, because, besides, but, especially, if, ok, or, so, and then. These findings are further illustrated by Figure 1 below.

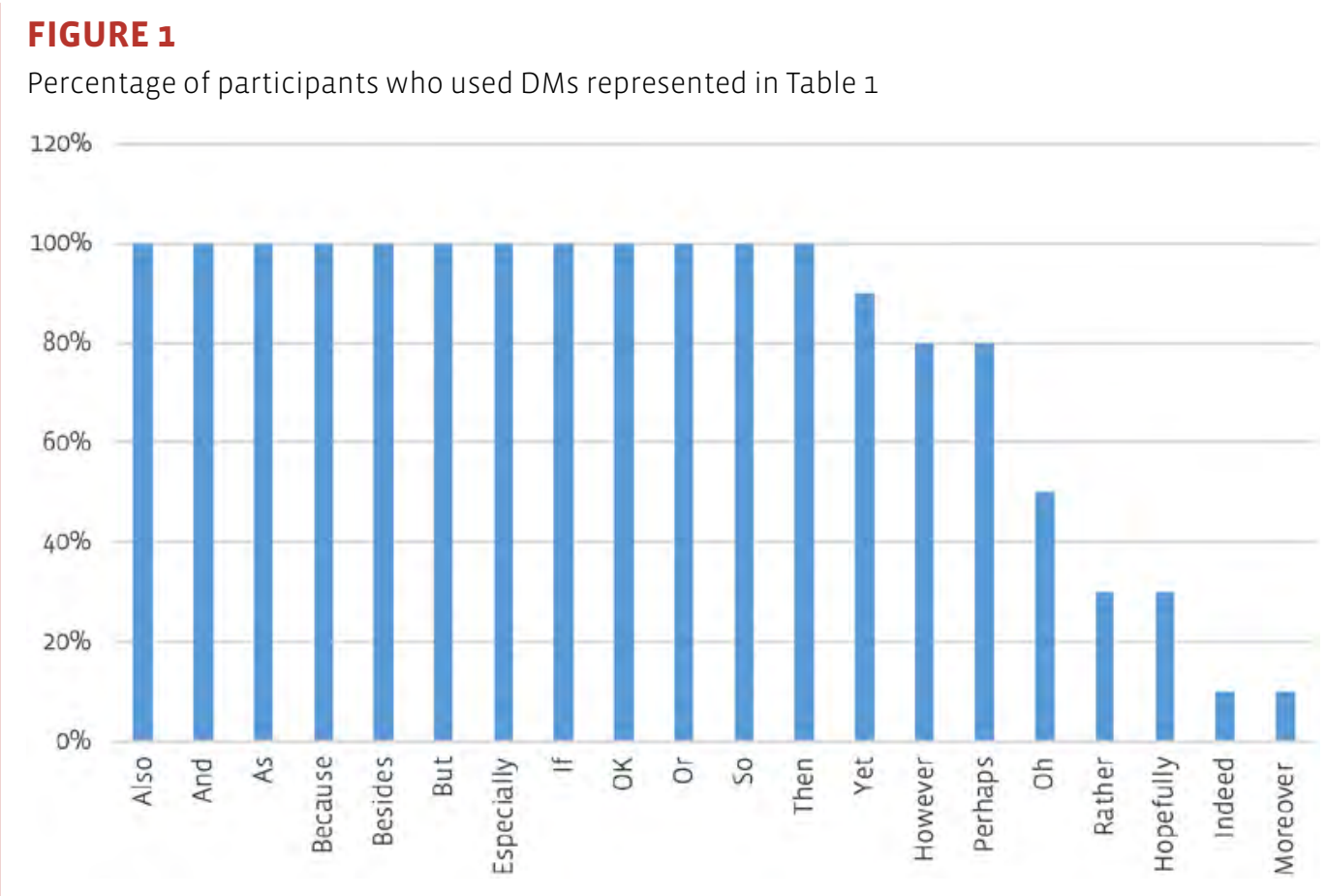

It is evident from Figure 1 and Tables $1-2$ that in addition to the DMs that the experienced EFL teacher and all participants use in their oral classroom discourse (i.e., also, and, as, because, besides, but, especially, if, ok, or, so, and then), there are also those DMs from the experienced $E F L$ teacher's repertoire that are reported to be employed by a substantial number of participants. These DMs are yet (used by $90 \%$ of all participants), however and perhaps, respectively (employed by $80 \%$ of the participants), and oh (used by $50 \%$ of all participants). These findings could be taken to indicate that a considerable part of the participants' repertoire of English DMs in their oral classroom discourse qualitatively converges on that of the experienced EFL teacher. Arguably, the participants' convergence on the experienced teacher's repertoire of English DMs could be explained by the specificity of oral classroom discourse. This assumption is evocative of the observation made by Llinares-García and Romero-Trillo (2008), who argue that EFL settings are conducive to using a certain register of instructional discourse that has communicative implications. As far as the instructional "teacher-student" 
type of discourse is concerned, DMs can be used in classroom management and classroom discourse organisation (Vickov \& Jakupčević, 2017). Presumably, the use of English DMs, for instance, also, and, as, because, in oral classroom discourse by the participants and the experienced EFL teacher could imply that the afore-mentioned DMs appear to be relevant in an EFL classroom setting in terms of their meaning and pragmatic functions. This assumption is in concert with Carter and McCarthy (2006), as well as with Crible and Cuenca (2017), who argue that the multifunctionality of DMs allows the interlocutors to use them in a diverse range of instructional contexts that are conceptualised as a critical element in oral discourse (Crible \& Cuenca, 2017).

Given that oral classroom discourse involves communicative interaction between a teacher and a student, a teacher and a student group, and amongst the student group (Kapranov, 2019), it is possible to assume that these types of interaction are associated with a certain range of DMs that are perceived by the participants as appropriate to use in instructional contexts. In particular, the participants mention the naturalness of use of such DMs as, for instance, also, and, as, because, besides, but, especially, if, oK, or, so, and then. To illustrate this observation, let us refer to the comments made by the participants. For example, Participant 1 writes: "As. It's a very natural word to use, and the students should have no problems understanding it."; "Or. The word is fundamental to the English language and not using it would be a tragedy on a par with that of Shakespeare" (Participant 1). Similarly, Participant 4 indicates that "the word 'also' is a very natural word for me to use, therefore I would use it". A similar reference to the naturalness of use of the DM because is expressed by Participant 2, who posits that "it is such a normal word to use...".

Judging from the participants' comments concerning the use of the DMs represented in Table 2, the participants indicate that they excessively use certain DMs, such as the DM and. For instance, Participant 3 writes: "I think I overuse it and therefore, my students will do the same. But I do think that I would use it more in oral communication than in writing". Another participant comments that and is "a basic word used in almost all contexts from early primary school" (Participant 5). In a similar manner, the participants explain their use of the DM because, as seen in excerpts (1) and (2) below:

(1) I use "because" a lot, I'm so used to hearing it and reading it that I automatically use it a lot. I don't think the students have any difficulties with the word 'because'. It is such a normal word to use in both oral and written communication. (Participant 2)

(2) I use it in classroom discussions and explanations as well to show the students how one can use it in the argument. (Participant 9)

The participants' self-reported overuse of certain DMs in their oral classroom discourse supports previous research conducted by Tavakoli and Karimnia (2017), who suggest that EFL teachers typically use the DMs and, but, because in EFL instructional settings. Furthermore, 
the present findings provide support to Vickov and Jakupčević (2017), who also point to the use of the DMs and, ok, and so by EFL teachers. Additionally, the findings in this study are in unison with Fung and Carter (2007), who have found that the DM and is amply employed by EFL teachers (Fung \& Carter, 2007: 410). Similarly, the presence of the DM and supports the studies conducted by Ding and Wang (2015), Liu (2013), and Shahbaz, Sheikh, and Ali (2013), where high occurrence of the DM and is reported in EFL classroom discourse.

In addition to the self-reported overuse of several DMs, some of the participants comment on the difficulties experienced by the students in Year 8 as far as the meaning of a number of DMs is concerned. These difficulties are also reflected in the questionnaire, where all participants indicate that the students in Year 8 are not aware of the translation of the DMs however, moreover, and rather. Similarly, 10\% of all participants argue that the students are unaware of the translation of the DMs hopefully, perhaps, and yet, whereas the DM indeed is mentioned by $20 \%$ of all participants as posing difficulties due to the students' unawareness of its translation. Notably, $60 \%$ of all participants observe that the Norwegian translation of the DM besides is not known to Year 8 students, whilst $20 \%$ of the participants indicate that Year 8 students experience difficulties with this DM, and $40 \%$ think that Year 8 students would not use besides in writing. As far as the use of the DM besides by Year 8 students is concerned, Participant 6 writes: "I do not think that they will have any difficulties, however, I don't think it's a word they would use". These findings are exemplified by Figure 2.

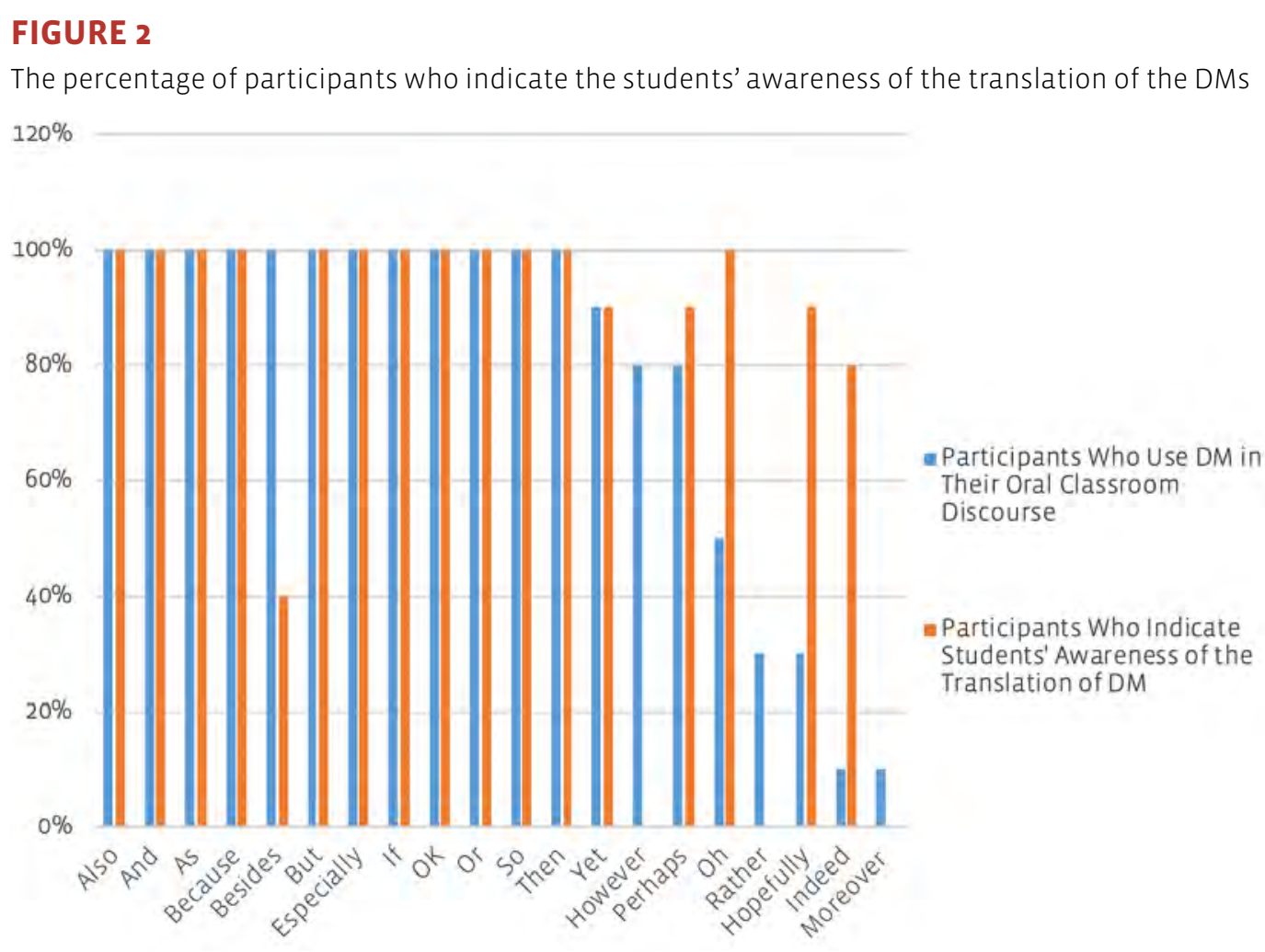


It is seen in Figure 2 that all participants use the DMs also, and, as, because, but, especially, if, ok, or, so, and then, and their use of these DMs corresponds to the participants' contention that the students in Year 8 are aware of the translation of these DMs. However, it is evident from Figure 2 that the participants' decrease in the use of the DMs however, hopefully, rather, indeed, and moreover, respectively, seems to correlate with the participants' perceptions that the students in Year 8 either do not know the translation of these DMs (e.g., however, rather) or only some students know what these DMs mean (e.g., hopefully, indeed). This observation is supported by the data summarised in Table 2 .

As evident from Table 2, the majority of the participants indicate that they do not use the following DMs during their teaching practice at school, e.g. indeed (90\%), moreover (90\%), and rather (70\%). Presumably, the absence of these DMs in the participants' repertoire of DMs in oral classroom discourse is explained by the formal register that is typically associated with these DMs. This assumption should be further discussed in conjunction with one of the research aims in the present study, namely the analysis of the participants' repertoire of English DMs in their oral classroom discourse through the lenses of informal and formal registers of the English language. Data analysis reveals that the participants seem to be reluctant to use those DMs that they deem to be associated with the formal register of English. For instance, Participant P 2 indicates: "I think I would use an easier word instead of 'rather' that might be similar to 'instead' or something" (Participant 2). Commenting on the absence of the DM moreover in their oral classroom discourse, several participants mention that this DM is not commonly used in Norwegian EFL classrooms, e.g.:

(3) I think the students would be completely unfamiliar with this word and be unable to use it. I would never use this word with students as they struggle with it and I barely use the word myself. (Participant 10)

(4) I think this word is not that commonly used and therefore unknown. Its equivalent is not much used in Norwegian. (Participant 8)

These findings could be interpreted as evidence of the participants' awareness of the distinction between the formal and informal registers of the English language. These findings appear to be in contrast to the study conducted by Kalajahi and Abdullah (2012), who found that the majority of EFL teachers in that study are not fully aware of the register and use of English DMs in EFL teaching and learning.

In the present study, the participants' reluctance to use the formal DMs in their oral classroom discourse can be explained by instructional contexts of the teaching and learning of English in Year 8. In particular, the use of the formal DMs is associated by the participants with the level of difficulty posed by these DMs. By means of indirectly referring to the instructional contexts, Participant P10 posits that “...the students would be completely unfamiliar with this word”, and “...this word is not that commonly used...” in the context of EFL teaching and learning in Year 8. The participants' use of the formal DMs is further illustrated by Figure 3 below. 


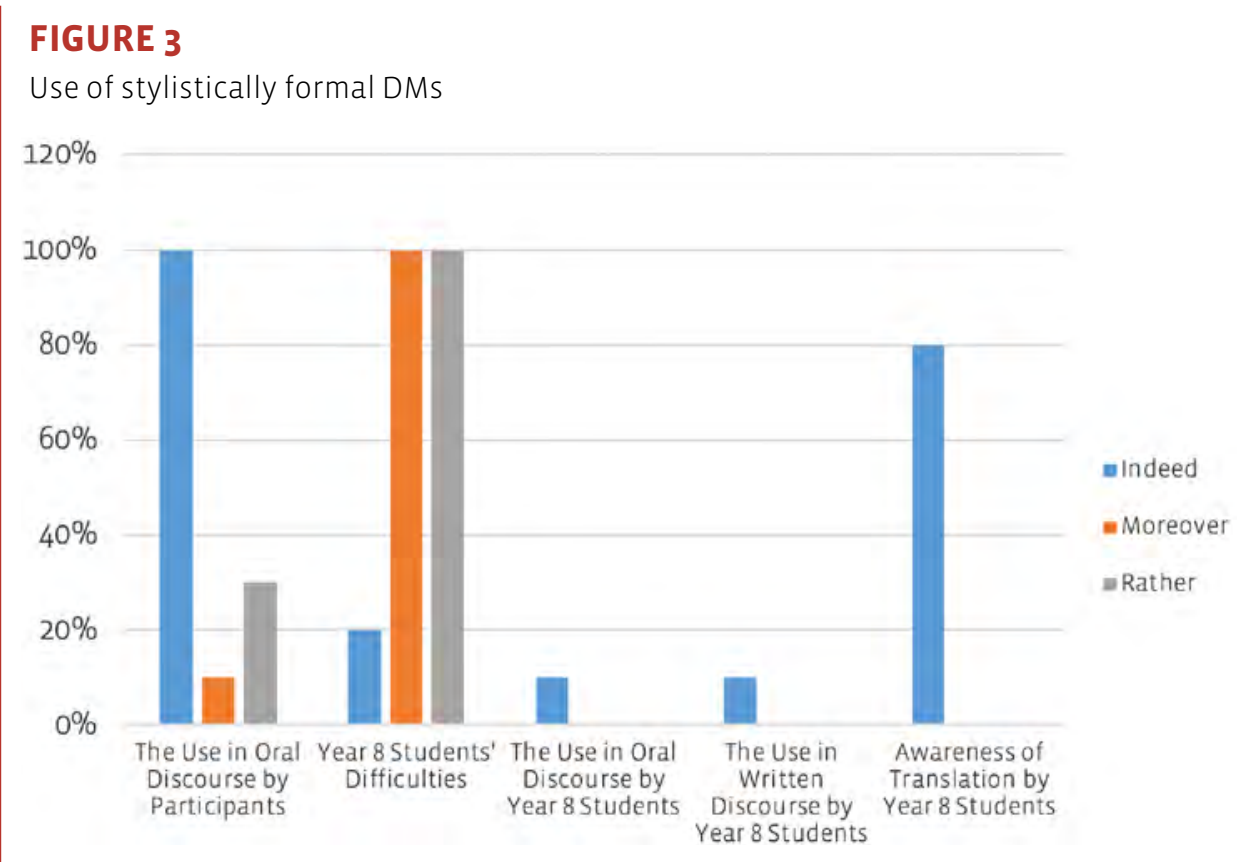

As evident from Figure 3 and Table 2, the participants consider the DMs moreover and rather to be challenging to the students in Year 8. Specifically, the participants indicate that the students in Year 8 use neither moreover nor rather in their oral and written discourse. Presumably, the participants consciously choose not to use those DMs that they consider difficult for the students in Year 8 due to their formal register, which is unfamiliar to the students. Whereas the participants appear to refrain from the use of formal DMs, such as indeed, moreover, and rather, they, nevertheless, use the DM however. Specifically, 80\% of all participants use it notwithstanding the fact that all of them (100\%) view this DM as difficult for the students in Year 8.

Whilst the participants appear to refrain from the use of the majority of formal DMs (e.g., moreover, rather), their use of informal English is concomitant with variability. In particular, the use of the informal DM oh is equally distributed among the participants: $50 \%$ of the participants report using it and $50 \%$ do not use it in their classroom communication with the students in Year 8. Excerpts (5) and (6) below illustrate the participants' use of this DM:

(5) I do not use this word in my classroom communication with the students. I do not use this word a lot in my oral speech as I find no room for it, nor do I feel it flows well. (Participant 2)

(6) I think I use this word without thinking: "Oh, and you have to be quiet”, or "Oh, I don't know". (Participant 7)

Whereas the use of the DM oh is equally distributed, $80 \%$ of the participants use the DM perhaps, and $100 \%$ of the participants indicate that the students in Year 8 do not seem to have difficulties with using this DM. However, only $20 \%$ of the participants report that Year 
8 students use the DM perhaps in their oral discourse, and $40 \%$ of the participants posit that Year 8 students employ perhaps in writing, even though this DM appears to be known to the students in Year 8 (i.e., 90\% of the participants reveal that the students in Year 8 know how this DM is translated from English into Norwegian).

\section{Conclusions and linguo-didactic implications}

This article presents and discusses a computer-assisted case study that seeks to establish the use of English DMs in oral classroom discourse in Year 8 in Norwegian EFL settings by the participants, who are pre-service EFL teachers. The participants' use of the DMs is investigated by means of analysing their answers to the questionnaire that is designed to address the use of DMs in oral classroom discourse after their school practice at a range of lower secondary schools in Norway. The theoretical premises of the study are based upon the approach to DMs formulated by Schiffrin (1987, 2001), who views DMs as "sequentially dependent elements that bracket units of talk" (Schiffrin, 1987: 31).

It has been hypothesised in the study that the participants' use of the English DM in a typical EFL classroom in Year 8 would be guided by the linguo-pragmatic instructional contexts of EFL teaching and learning. Amongst the specific research aims of the study there are the considerations of the participants' repertoire of English DMs in their oral classroom discourse that could be i) qualitatively different from and/or similar to that of the experienced $\mathrm{EFL}$ teacher and ii) marked by formal and/or informal registers of the English language. Informed by Schiffrin's (1987) approach to DMs, the quantitative analysis of the participants' questionnaires in statistical software program SPSS version 18.0 (2009) has yielded the results that indicate that the participants' repertoire of English DMs in their oral classroom discourse is similar to that of the experienced in-service EFL teacher, who teaches EFL in Year 8. Specifically, it has been found that all participants use 12 DMs that are also present in oral classroom discourse by the experienced in-service EFL teacher. These DMs are also, and, as, because, besides, but, especially, if, ok, or, so, and then.

The majority of the participants indicate that they never use the DMs indeed, moreover, and rather during their teaching practice at school. The participants' comments suggest that the absence of the DMs indeed, moreover, and rather in their repertoire of DMs in oral classroom discourse is explained by the formal register these DMs are typically associated with. Arguably, the absence of the DMs that represent the formal register of English is suggestive of the participants' awareness of the level of difficulty posed by these DMs to the students in Year 8. It can be generalised that the participants' use of English DMs in oral classroom discourse is not marked by the presence of the formal DMs, such as moreover and rather. It follows from these findings that the participants' use of DMs appears to be guided by the linguo-pragmatic instructional contexts of EFL teaching and learning in Year 8 that factor in the students' potential difficulties associated with the formal DMs. 
Whilst the afore-mentioned specific research aims have been achieved in the study, it has several shortcomings. First, the number of participants $(\mathrm{N}=10)$ does not allow to offer significant generalisations. The present findings do not pretend to provide an encompassing account of the repertoire of English DMs used by pre-service EFL teachers whose LI is Norwegian. Obviously, more studies are needed to establish possible patterns of use of English DMs in EFL classroom in Norway by pre-service EFL teachers. Second, future studies are needed that will investigate the use of DMs by EFL students at lower secondary schools. Arguably, it would be advisable to compare the use of English DMs by the lower secondary students with that of their EFL teachers.

Despite the afore-mentioned shortcomings, however, the present study might offer several linguo-didactic implications. The first implication could be formulated as follows. Given that the in-service EFL teacher and the participants, pre-service EFL teachers, share a substantial number of DMs in common, it seems possible to suggest that DMs constitute an integral part of oral classroom discourse in an EFL classroom at a lower secondary school. Presumably, there is a need to address what DMs should be taught to future EFL teachers, how they should be taught, and how the teaching and learning of English DMs should be integrated into an EFL classroom in Norwegian lower secondary school contexts.

Another linguo-didactic implication that is based upon the present findings involves a suggestion to avoid using those English DMs that are associated with the formal register of the English language in oral classroom discourse at a lower secondary school. It is, perhaps, advisable for an EFL teacher to use stylistically neutral and colloquial DMs (and, but, OK, etc.) in their oral classroom discourse, since these DMs appear to be familiar to the students, who use them in oral and written modes of communication in English.

\section{Acknowledgements}

The author of the article acknowledges the 10 participants who took part in the study. The author of the present article acknowledges research funding provided by Western Norway University of Applied Sciences that enabled them to present parts of this research at The Second International Conference "New Trends in Foreign Language Teaching" that was held in Granada (Spain) in May 2018. The author expresses their gratitude to the conference organisers and participants for their positive feedback given at the conference, as well to the editor of the present volume and two anonymous reviewers for their invaluable comments and suggestions.

\section{References}

Aşık Asuman, \& Pasa Tevfik Cephe, 2013: "Discourse Markers and Spoken English: Nonnative Use in the Turkish EFL Setting", English Language Teaching 6 (12), 144-155. 
Biber, Doug, 2006: University Language: A Corpus-Based Study of Spoken and Written Registers, Philadelphia: John Benjamins.

Campillos Llanos, Leonardo, \& Paula GonzÁlez Gómez, 2014: “Oral production of discourse markers by intermediate learners of Spanish: A corpus perspective" in Jesús Romero Trillo (ed.): Yearbook of Corpus Linguistics and Pragmatics 2014, Cham: Springer: 239-259.

CARTer, Ronald, \& Michael McCARThy, 2006: Cambridge grammar of English: a comprehensive guide; spoken and written English grammar and usage, Cambridge: Cambridge University Press.

Castro, Chapetón, \& Claudia Marcela, 2009: "The use and functions of discourse markers in EFL classroom interaction”, Profile Issues in Teachers' Professional Development 11, 57-78.

CRIBLE, Ludivine, \& Maria-Josep CuenCA, 2017: “Discourse Markers in Speech: Distinctive Features and Corpus Annotation”, Dialogue \& Discourse 8 (2), 149-166.

DING, Rongrong, \& Lixun Wang, 2015: “Discourse Markers in Local and Native English Teachers' Talk in Hong Kong EFL", International Journal of Language and Linguistics 2 (5), 65-75.

Fox TREe, Jean E., 2010: "Discourse markers across speakers and settings", Language and Linguistics Compass 4 (5), 269-281.

Fraser, Bruce, 1999: “What are discourse markers?”, Journal of Pragmatics 31 (7), 931-952.

Fung, Loretta, \& Ronald CARTER, 2007: “Discourse markers and spoken English: Native and learner use in pedagogic settings", Applied Linguistics 28 (3), 410-439.

HaYs, Paul, 1992: “Discourse markers and L2 acquisition”, Papers in Applied Linguistics 7, 24-34.

Hellermann, John, \& Andrea Vergun, 2007: "Language which is not taught: The discourse marker use of beginning adult learners of English”, Journal of Pragmatics 39, 157-179.

Kalajahi, Seyed Ali Rezvani, \& Ain Nadzimah Abdeullah, 2012: "Perceptions of Iranian English Language Teachers towards the Use of Discourse Markers in the EFL Classroom", Theory and Practice in Language Studies 2 (10), 2002-2010.

Kapranov, Oleksandr, 2019: "Discourse Markers in Argumentative Essays in EFL by Norwegian Pre-Service Primary School Teachers" in Christoph HaAse \& Natalia Orlova (eds.): English Language Teaching through the Lens of Experience, Newcastle upon Tyne: Cambridge Scholars Publishing, 83-100. 
Kapranov, Oleksandr, 2018: "The Impact of Implicit Instruction upon the Use of English Discourse Markers in Written Tasks at the Advanced Beginners' Level of EFL Proficiency", Baltic Journal of English Language, Literature and Culture 8, 56-73.

Kapranov, Oleksandr, 2017: "Discourse Markers in EFL Academic Essays Written by Primary School Teacher Candidates", Konin Language Studies 5 (4), 473-493.

Koczogh, Helga Vanda, 2007: "Native speaker and non-native speaker discourse marker use. The use of discourse marker 'well'”, Argumentum 3, 46-53.

LIU, Binmei, 2013: "Effect of first language on the use of English discourse markers by LI Chinese speakers of English", Journal of Pragmatics 45 (1), 149-172.

Llinares-García, Ana, \& Jesús Romero-Trillo, 2008: "Discourse markers and the pragmatics of native and non-native teachers in a CLIL corpus" in Jesús Romero-Trillo (ed.): Pragmatics and Corpus Linguistics: A Mutualistic Entente, Berlin: Mouton de Gruyter: 191-204.

Maschler, Yael, 2000: "Toward fused lects: Discourse markers in Hebrew English bilingual conversation twelve years later”, International Journal of Bilingualism 4 (4), 529-561.

Maschler, Yael, \& Deborah Schiffrin, 2015: "Discourse Markers. Language, Meaning, and Context” in Deborah TAnnen, Heidi E. Hamilton, \& Deborah Schiffrin (eds.): The Handbook of Discourse Analysis, Oxford: Wiley Blackwell: 189-221.

Matras, Yaron, 2000: "Fusion and the cognitive basis for bilingual discourse markers", International Journal of Bilingualism 4 (4), 505-528.

ÖZer, Havva Zorluel, \& Zuhal OkAn, 2018: "Discourse markers in EFL classrooms: A corpus-driven research", Journal of Language and Linguistic Studies 14 (1), 50-66.

Romero-Trillo, Jesús, 2007: "Adaptive Management in Discourse: The Case of Involvement Markers in English and Spanish Conversations", Catalan Journal of Linguistics 6, 81-94.

Rose, Kenneth R., 2005: "On the effects of instruction in second language pragmatics", System 33, 385-399.

Sankoff, Gillian, Pierrette Thibault, Naomi Nagr, Helene Blondeau, Mari-Odille Fonollosa, \& Lucie GAGNON, 1997: "Variation in the use of discourse markers in a language contact situation", Language Variation and Change 9 (2), 191-217.

ScHIFFRIN, Deborah, 1987: Discourse Markers, Cambridge: Cambridge University Press. 
Schiffrin, Deborah, 2001: "Discourse markers: language, meaning, and context" in Deborah Schiffrin, Deborah Tannen, \& Heidi E. Hamilton (eds.): The Handbook of Discourse Analysis, Oxford: Blackwell, 54-75.

Scort, Mike, 2008: WordSmith tools version 5, Liverpool: Lexical Analysis Software 122.

Shahbaz, Muhammad, Omar Islam SheIKH, \& Muhammad Shahbaz Alı, 2013: "The Use of Discourse Markers by Chinese EFL Professors: A Corpus-Based Study of Academic Lectures by Natives and Non-natives", Journal of Education and Practice 4 (5), 80-90.

SPSS, 2009: PASW Statistics for Windows, Version 18.0, Chicago: SPSS Inc.

Suparno, Karlina, \& Endang Setyaningsin, 2015: “The Little Words That Matter: Discourse Markers in Teacher Talk", Journal Paedagogia 18 (2), 81-89.

Tavakoli, Mahboobeh, \& Amin KarImniA, 2017: "Dominant and Gender-Specific Tendencies in the Use of Discourse Markers: Insights from EFL Learners", World Journal of English Language 7 (2), 1-9.

VICKVov, Gloria, \& Eva JAKUPČEvIć, 2017: "Discourse markers in non-native EFL teacher talk”, Studies in Second Language Learning and Teaching 4, 649-671.

WaLSH, Steve, 2002: "Construction or obstruction: Teacher talk and learner involvement in the EFL classroom”, Language Teaching Research 6 (1), 3-23. 